\title{
Subjective duration as a signature of coding efficiency: Emerging links among stimulus repetition, predictive coding, and cortical GABA levels.
}

ARTICLE · DECEMBER 2014

CITATIONS

4

6 AUTHORS, INCLUDING:

Devin Blair Terhune

University of Oxford

38 PUBLICATIONS 410 CITATIONS

SEE PROFILE

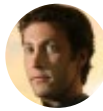

David M Eagleman

Baylor College of Medicine

98 PUBLICATIONS 2,103 CITATIONS

SEE PROFILE
DOWNLOADS

56
VIEWS

124
Hedderik van Rijn

University of Groningen

118 PUBLICATIONS 1,000 CITATIONS

SEE PROFILE

Warren Meck

Duke University

187 PUBLICATIONS $\quad \mathbf{1 4 , 2 8 1}$ CITATIONS

SEE PROFILE 


\title{
Subjective Duration as a Signature of Coding Efficiency: Emerging Links Among Stimulus Repetition, Predictive Coding, and Cortical GABA Levels
}

\author{
William J. Matthews' Devin B. Terhune ${ }^{2}$, Hedderik van Rijn ${ }^{3}$, David M. Eagleman ${ }^{4}$, \\ Marc A. Sommer ${ }^{5}$, and Warren H. Meck ${ }^{6 *}$ \\ 'Department of Psychology, University of Cambridge, Cambridge, UK \\ 2Department of Experimental Psychology, University of Oxford, Oxford, UK \\ ${ }^{3}$ Department of Experimental Psychology, University of Groningen, Groningen, NL \\ ${ }^{4}$ Department of Neuroscience, Baylor College of Medicine, Houston, TX, USA \\ ${ }^{5}$ Department of Biomedical Engineering, Duke University, Durham, NC, USA \\ ${ }^{6}$ Department of Psychology and Neuroscience, Duke University, Durham, NC, USA \\ *meck@psych.duke.edu \\ Received: Summer 2014; Accepted: Summer 2014; Published: December 24, 2014.
}

\begin{abstract}
Immediate repetition of a stimulus reduces its apparent duration relative to a novel item. Recent work indicates that this may reflect suppressed cortical responses to repeated stimuli, arising from neural adaptation and/or the predictive coding of expected stimuli. This article summarizes recent behavioral and neurobiological studies linking perceived time to the magnitude of cortical responses, including work suggesting that variations in GABA-mediated cortical inhibition may underlie some of the individual differences in time perception. We suggest that the firing of cortical neurons can be modified using simple recurrent networks with time-dependent processes that are modulated by GABA levels. These local networks feed into a core-timing network used to integrate across stimulus inputs/modalities, thereby allowing for the coordination of multiple duration ranges and effector systems.
\end{abstract}

Keywords: Predictive coding; Repetition suppression; GABA; Individual differences; Timing and time perception; Interval tuning; Cortical and sub-cortical structures; Striatal beat-frequency model

\section{Introduction}

The first occurrence of a repeated item typically seems to last longer than subsequent presentations (Rose \& Summers, 1995), and a novel stimulus shown after repeated presentations of a standard item has a similarly expanded subjective duration (Eagleman, 2008; Eagleman et al., 2005). These effects have been interpreted in terms of attention to novelty (Tse et al., 2004) and/or the arousaldriven acceleration of an internal pacemaker (Ulrich et al., 2006). One idea, which potentially links repetition effects to wide-ranging principles of timing and neural processing, is that perceived duration is a signature of neural coding efficiency, with stimuli that evoke larger neural responses perceived to last longer than those that elicit less activity (Eagleman \& Pariyadath, 2009, see also Rammsayer, 1994, for a discussion of earlier work linking energy-dependent cues to temporal duration). This article summarizes recent behavioral and neural studies of the links between repetition, coding efficiency, and time perception, and describes how these results cast new light on individual differences in timing and time perception.

Timing \& Time Perception Reviews is a joint publication of the University of Groningen and Brill Publishers NV.

Copyright: (c) 2014 Matthews et al. This article is distributed under the terms of the Creative Commons Attribution 4.0 International License (CC BY 4.0) which permits any use, distribution, and reproduction in any medium, provided the original author(s) and the source are credited.

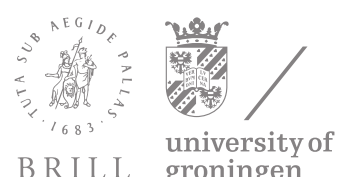

B R I L L groningen 


\section{Behavioral Studies of Repetition Effects}

Eagleman and Pariyadath (2009) noted that many of the manipulations that lengthen perceived duration also evoke larger cortical responses. For example, increased brightness, size, motion, and novelty typically expand subjective duration and evoke larger neural responses, either because of increased firing rates or because larger areas of the cortex respond to the stimulus. On the basis of these correlations, Eagleman and Pariyadath proposed that the experience of time is a product of the neural energy used when representing the stimulus -- that is, of the efficiency with which it is encoded (see also Pariyadath \& Eagleman, 2007).

Within this framework, repetition is particularly important because repetition exerts strong effects on coding efficiency. Evoked responses often diminish with successive presentations of a stimulus, an effect known as repetition suppression (RS). RS is the subject of intense theoretical and empirical investigation (see Grill-Spector et al., 2006, for a review). The relatively reduced response to repeated stimuli may partly be due to simple adaptation/neural fatigue (e.g., De Baene \& Vogels, 2010; Larsson \& Smith, 2012), but it is also thought that RS results from active predictive coding (e.g., Rao \& Ballard, 1999). According to the latter view, recent exposure generates an (implicit) expectation that the same item will recur, leading to more efficient coding of a repetition and a prediction-error signal when the sensory input deviates from this expected pattern (e.g., Wacongne et al., 2011 but see Kovács et al., 2013 for some qualifications regarding different visual stimulus categories).

Most behavioral studies of repetition effects on time perception have used an "oddball" paradigm in which a standard stimulus (e.g., a red disc) is repeated several times followed by a novel item (e.g., a black disc) (Pariyadath \& Eagleman, 2007; Schindel et al., 2011; Tse et al., 2004). The duration of the novel item is typically overestimated relative to the standards by $10-50 \%$, an effect that generalizes across sensory modalities and timescales ranging from approximately $200 \mathrm{~ms}$ to (at least) $2000 \mathrm{~ms}$ (Tse et al., 2004). Moreover, recent work has shown that this effect generalizes across judgment tasks, suggesting a genuinely "perceptual" effect (Birngruber et al., 2014).

Recent behavioral studies using the oddball paradigm have provided support for the coding-efficiency account of repetition effects. The oddball effect increases with increasing presentations of the standard, consistent with progressively stronger RS of increasingly predictable items (Kim \& McAuley, 2013; Pariyadath \& Eagleman, 2012). In addition, for oddball tasks in which a deviation in line orientation has to be detected, the oddball effect is positively related to the discrepancy between the angle of the repeated and novel items, consistent with the idea that the effect is driven by the size of the mismatch between observed and predicted sensory input (Pariyadath and Eagleman, 2012; Schindel et al., 2011; but see Kim \& McAuley, 2013). Further evidence for a prediction-based account is provided by Schindel et al. (2011) who found that, unlike low-level adaptation effects, the expanded subjective duration of oddballs is unaffected by whether the standards and oddballs were presented to different eyes. Moreover, the temporal expansion can occur for oddballs that are less intense than the standards, again arguing for a prediction- or change-based account rather than a simple association between low-level response magnitudes and subjective time (see also Matthews et al., 2011; Rammsayer, 1994).

The oddball task has several limitations. For example, oddballs always occur later in the stimulus sequence than standards, and participants are required to compare a single novel stimulus against a large number of repeated standards. Matthews (2011b) circumvented these problems by presenting just two stimuli per trial, with the second stimulus either the same as or different from the first. The point of subjective equality (PSE), a psychophysical index corresponding to the comparison stimulus duration that is perceived to be equivalent to the standard stimulus duration, was greater for repeats, indicating that novel stimuli were perceived to have longer duration. However, the just-noticeable difference, or difference limen (DL), was unaffected by repetition, indicating no difference in the precision of temporal representation. Interestingly, when the second image was new on that trial, but a repeat of a stimulus seen 20 trials previously, subjective duration was the same as for novel stimuli, suggesting a short timescale for repetition effects - contrary to the longlasting effects of prior exposure sometimes seen in studies of RS (e.g., Henson et al., 2004. Moreover, when participants estimated the duration of the second image on a categorical scale, the repetition effect was independent of physical duration, contrary to what would be expected if repetition slowed the rate of an internal pacemaker (e.g., Matthews, 2011a).

These data provide a "clean" demonstration that subjective duration is shorter for immediate repeats than for novel stimuli, consistent with a coding-efficiency account. However, there are pronounced individual differences in the magnitude of this effect (see Matthews \& Meck, 2014, for examples). In particular, an individual's oddball effect positively correlated with his or her DL: observers with poorer temporal discrimination were 
particularly prone to over-estimate the duration of novel stimuli relative to repeats (Matthews, 2011b). As we describe shortly, recent neurobiological studies may cast light on these individual differences.

\section{Neuroimaging Studies of Repetition Effects}

The neurophysiological foundations of psychological repetition priming experiments and the RS phenomenon have been tested with a large number of non-invasive and invasive neuroimaging techniques. Although the physiological basis of RS has not been fully established, these techniques provide a powerful means for mapping the neural circuits underlying specific representation of stimulus attributes, such as time, space, number, and intensity (e.g., Merzagora, et al., 2014; Naccache \& Dehaene, 2001). In RS, brain areas that activate when a participant observes a stimulus presentation (e.g., parts of the visual cortex) generally show a diminished response when that participant later views an identical or similar stimulus, the prediction of which may also engage the prefrontal cortex (Luk and Wallis, 2013; Lustig et al., 2005). Cognitive neuroscientists have established putative information-processing circuits for perception, attention, and decision-making based, in part, on the identification of brain areas that exhibit RS as a function of specific types of stimulus presentation (e.g., Bastos et al., 2012; GrillSpector et al., 2006). Research has used RS to reveal detailed information regarding the types of neuronal processes that occur in different brain areas, such as the findings that perceptual memory information is represented in sensory regions (Tootell et al., 1998) and that abstract stimulus properties are coded by neurons in temporal and frontal cortices (Henson et al., 2004). Further, the magnitude of RS predicts the strength of a person's memory on a trial-by-trial basis (Maccotta \& Buckner, 2004) and shows the involvement of different brain regions in distinct memory processes (Gonsalves et al., 2005). Although RS is not a perfect measure of neuronal coding (Sawamura et al., 2006), obtaining a more detailed understanding of RS is likely to shed light on the fundamental nature of human memory and cognition and is considered a key goal of cognitive neuroscience (Segaert et al., 2013). Various neural models have been proposed to explain how the RS observed with fMRI is related to the brain's electrical activity (Grill-Spector et al., 2006). These models differ in terms of how they attribute RS to changes in the amplitude, timing, and identities of the neurons that are active when viewing a repeated item. Distinguishing between these theories is complicated by uncertainty regarding the relation between the fMRI blood-oxygenation signal and underlying neuronal activity (Ekstrom, 2010; Logothetis, 2003; Logothetis et al., 2001). Thus, researchers have suggested that direct electrophysiological recordings could help to explain RS more fully (Gotts et al., 2012).

\section{Linking Repetition Suppression to Subjective Time}

Recent studies of human and primate neurophysiology lend weight to the idea that coding efficiency is an important determinant of timing and time perception. Indirect evidence that subjective duration is correlated with the size of the stimulus-specific neural response has been provided by Sadeghi et al. (2011), who presented human participants with a sequence of 200-ms pulses of dot motion stimuli followed by a comparison pulse of variable duration. The comparison stimulus was judged longer when its direction of motion differed from the standards, and when the same stimuli were presented to monkeys (albeit while the animals performed a different task), neurophysiological recording from the middle temporal area of the visual cortex $\left(\mathrm{MT}_{\mathrm{T}} \mathrm{V}_{5}\right)$ revealed that the firing rate and response-duration of these neurons was greater for the oddballs than the repeats. This suggests that perceived duration is determined by the magnitude of the neural response to a stimulus.

More recent work by Mayo and Sommer (2013) has directly linked the magnitude and timing of neural responses in the primate cortex to perceived duration. These authors recorded from visually-responsive neurons of the frontal eye field (FEF) of monkeys trained to classify the interval between two brief light flashes as longer/shorter than a learned 350-ms standard. The probe intervals ranged from $25^{0}-45^{\circ} \mathrm{ms}$, and the monkeys indicated their response by making a saccade to one of two targets. As one would expect, the latency between FEF responses to the first and second flashes was tightly linked to the time between those events. The key finding was that trial-by-trial variation in the perception of a given interval depended on the magnitude rather than the latency of the neural responses to the second flash. That is, FEF firing rates were higher when a given interval was judged "long" than when it was judged "short". This is unlikely to reflect response preparation (the short- and long-response targets were outside the visual fields of the recorded neurons, in the visual hemifield ipsilateral to the recording) and was not found in the superior colliculus; rather, the data suggest a strength-code for temporal information that is specific to the prefrontal cortex. The authors suggest that this code is based on adaptation, noting that the 
magnitude effect had diminished for intervals $>400 \mathrm{~ms}$, when adaptation would be expected to be minimal (see Aghdaee et al., 2014; Mayo \& Sommer, 2008; Smith \& Sommer, 2013).

These recent papers complement previous work on human timing by Noguchi and Kakigi (2006), who used magnetoencephalography (MEG) to record visuallyevoked activity during a temporal discrimination task in which human observers judged whether the second of two visually presented stimuli had a "longer" or "shorter" duration than the first. They assessed both behavioral responses and the "neural interval", defined as the time between the evoked neural responses to the onset and offset of the durations. The probability of a "long" response was greater when the first and second stimuli were different shapes than when they were the same. However, the neural interval was actually longer when the second stimulus was a repeat of the first, as the onset response was shorter on same trials but the offset responses were independent of stimulus type. By contrast, the size of the onset response was smaller for repeated stimuli, providing further support for a strength-based temporal code in which adaptation contracts the subjective duration of repeated stimuli.

Further support for the role of predictive coding and the suppression of responses to expected stimuli in the context of human timing is provided by Kononowicz and Van Rijn (2014). In their temporal discrimination task, all durations were demarcated by two short auditory tones. Focusing on the auditory potentials evoked by the offset of the comparison duration, Kononowicz and Van Rijn demonstrated that the amplitude of the neural response followed the absolute deviation between standard and comparison duration, with the comparison durations closest to the standard duration eliciting the smallest neural response. In addition, they also demonstrated that these evoked neural responses predicted the subjective perception of the comparison interval, with smaller evoked responses perceived more similar to the standard interval, irrespective of the presented, objective duration.

Taken together, these studies provide converging evidence for magnitude-coding of temporal information of the type postulated by the coding-efficiency account of repetition effects - although the relative importance of implicit predictions and low-level adaptation remains unclear.

\section{Individual Differences: A New Frontier}

The evidence for a role of RS in timing and time perception is complemented by recent studies linking individual differences in timing to the inhibitory neurotransmitter gamma-aminobutyric acid (GABA). Earlier work showed that in vivo basal GABA levels, as measured by magnetic resonance spectroscopy (MRS; Puts \& Edden, 2012), negatively correlate with the size of evoked responses in the visual cortex (Donahue et al., 2010; Muthukumaraswamy et al., 2009) as well as other regions (e.g., Northoff et al., 2007). Specifically, the magnitude of the hemodynamic response of the fMRIBOLD signal in the visual cortex was reduced in individuals with larger GABA levels in this region, possibly through an effect on local circulation or glutamate levels (Muthukumaraswamy et al., 2009). Pharmacological studies complement this finding by showing that GABA agonists reduce perceptual awareness (van Loon et al., 2012) and visual discrimination (Giersch \& Herzog, 2004), and attenuate the neurophysiological response to visual oddball stimuli $\left(\mathrm{P}_{3}\right.$ event-related brain potential component; Watson et al., 2009). Further studies showed that GABA agonists also impair temporal discrimination of auditory intervals (Rammsayer, 1992, 1999). In addition to cortical regions, the dendritic spines of GABAergic projection neurons in the basal ganglia make contact with the corticostriatal-thalamostriatal glutamatergic and nigrostriatal dopaminergic neurons involved in interval timing (Meck, 1996). As a consequence, GABA levels in both the cortex and basal ganglia are able to modify different stages of temporal integration (Coull et al., 2011; Meck, 1983, 2006; Meck \& Benson, 2002). Moreover, cell adhesion molecules (e.g., CHLi) influence the organization of GABAergic axons and direct the innervation of dendrites during various phases of neural plasticity (Jovanovic \& Thomson, 2011). Mice deficient in CHLı have recently been shown to display impaired interval timing and spatial-temporal integration, possibly as a result of functional abnormalities in thalamo-cortical circuits (Buhusi et al., 2013).

Recent studies have built upon this work by explicitly linking individual differences in GABA-mediated cortical inhibition to inter-individual variability in timing and time perception. Van Loon et al. (2013), for example, correlated variation in basal GABA levels, as measured by MRS, to variation in the time course of visual perception. They found a positive correlation between GABA levels in the visual cortex and the time between perceptual "switches" in multiple tasks measuring bistable perceptual illusions such as binocular rivalry, in which observers are presented with ambiguous sensory input (e.g., different images presented to each eye) and subjective experience spontaneously fluctuates between competing states. This correlation was specific to the visual cortex (GABA levels in the dorsolateral prefrontal cortex were unrelated to 
percept duration), specific to GABA (there was no indication of a correlation for glutamate/glutamine), and specific to bistable perception (GABA levels did not predict reaction times in a control task). Moreover, stimulation of $\mathrm{GABA}_{\mathrm{A}}$ receptors by administration of lorazepam lengthened percept duration, pointing to a causal relation. Both the positive correlation found for natural fluctuations in basal GABA levels and perceptual switch time, and the results of the experimental manipulation using lorazepam, suggest that elevated GABA produces a slowing of perceptual dynamics, resulting in an attenuation of shifts in the contents of consciousness and thereby a dilation of individual percepts.

Furthermore, a direct link between individual differences in GABA and the role of coding efficiency in time perception has recently been described by Terhune and colleagues (2014), using a temporal discrimination task in which repeated presentation of a 500-ms (standard) visual stimulus was followed by a series of comparison intervals ranging from $395-605 \mathrm{~ms}$. In a separate session, basal GABA concentrations in the primary visual cortex and a control region were measured using MRS. GABA levels positively correlated with the PSE in the discrimination task, accounting for approximately $45 \%$ of the variance in performance. Specifically, participants tended to under-estimate the duration of the comparison intervals relative to the standard (a positive time-order error - Hellström, 1985), and this effect was more pronounced in people with higher GABA levels. Further analyses demonstrated the specificity of this effect. GABA concentrations did not correlate with the precision of temporal representation (assessed with the Weber fraction) or with performance on a temporal reproduction task. Moreover, neither GABA levels in the motor cortex nor glutamate levels in the visual cortex correlated with timing performance. Cumulatively, these results illustrate the task, topographic, and neurochemical specificity of this effect.

Because precision and reproduction performance were not influenced by GABA concentrations, but the comparison durations were perceived as shorter, Terhune et al. (2014) interpreted these results as evidence that GABA-mediated suppression of activity in the visual cortex leads to a contraction of the subjective duration of comparison intervals. This interpretation fits within the broader coding-efficiency framework and what is known about the relationship between GABA and visual perception, but it should be interpreted in a preliminary fashion. For one thing, the relation between PSE and GABA levels might be due to a subjective lengthening of the standard interval rather than a contraction of the comparison. Indeed, it could be argued that it is unclear why the GABA-mediated suppression would affect only one of the two interval types rather than leading to a contraction of subjective duration for both the standard and the comparison intervals and no net effect on PSE (notwithstanding that duration judgments may weight comparison and standard intervals differently, and/or be made in regard to an updated average of comparison durations rather than to a single standard interval - Allan, 1979; Dyjas \& Ulrich, 2014; Gu \& Meck, 2011; Shi et al., 2013). One speculative explanation is that GABA levels may mediate reduced neural responding to repeated stimuli, such that RS for the comparison stimulus is greater amongst observers with high GABA levels. It is also interesting that there was no correlation between GABA and temporal reproduction, given that the reproduction task used the time between two visually-presented stimuli to define the to-be-reproduced interval - although this may be explained by "memory mixing" (Gu \& Meck, 2011; Penney et al., 2000; Shi et al., 2013; Taatgen \& Van Rijn, 2011).

One further issue is whether GABA levels solely mediate this effect or whether it is driven by the balance of local cortical excitation and inhibition (e.g., Merchant et al., 2011; Yizhar et al., 2011). Indeed, there was a suggestive, albeit non-significant, relationship between glutamate/GABA ratios and perceived duration, such that lower values (reflecting greater inhibition) were associated with underestimation. Such an effect remains consistent with the coding-efficiency account described above and is worthy of further consideration. A final question is whether this effect generalizes to interval timing mechanisms that are independent of sensory processing. Indirect evidence bearing on this is provided by Tipples and colleagues (2013), who found that the magnitude of the fMRI BOLD signal in response to timed intervals in the SMA, inferior frontal gyrus, and basal ganglia (putamen and pallidum) during a duration bisection task was negatively associated with the PSE (see Lustig \& Meck, 2011; Ng et al., 2011; Penney et al., 2000, 2008). This suggests a relationship between the magnitude of the BOLD response and perceived duration and is consistent with the findings of Terhune et al. (2014) if the negative relationship between GABA and the BOLD signal generalizes to non-sensory regions (Northoff et al., 2007).

Taken together, the results of Van Loon et al. (2013) and Terhune et al. (2014) suggest that local basal GABA levels impact time perception by shaping visual perception. These results provide a strong platform for future work investigating the neurochemical basis of individual differences in timing as well as the effects of cortical and sub-cortical excitability on subjective duration. 
Importantly, recent modeling using artificial neural networks has shown that the activation of $\mathrm{GABA}_{\mathrm{B}}$ receptors (responsible for the production of slow inhibitory postsynaptic potentials) supports interval tuning (Merchant et al., 2011). In this case, neural responses to pairs of stimuli separated by a fixed duration were modified by altering the weights of the excitatory connections with paired-pulse facilitation, as well as the weights of the GABAb connections to the excitatory cells of the network. As a function of repeated activation, these recurrent networks came to function as 'perceptrons' for the specific durations that were presented, thus producing circuits that display temporal generalization functions similar to those observed in psychophysical data and accounted for by the striatal beat-frequency model of interval timing (e.g., Allman \& Meck, 2012; Matell \& Meck, 2004, Meck et al., 1998; Meck \& Malapani, 2004; Van Rijn et al., in press; Yin \& Meck, 2014).

\section{Future Directions: Unified Accounts}

Meck and colleagues (Allman et al., 2014; Coull et al., 2011; $\mathrm{Gu}$ et al., in press b; Lewis \& Meck, 2012; MacDonald et al., 2014; Matell \& Meck, 2000, 2004; Meck et al., 2008, 2013; Merchant et al., 2013; Van Rijn et al., in press) have proposed a unified timing model in which the perception and estimation of time depends on the interaction of multiple brain areas as outlined in Figure 1. These include structures that are consistently involved in temporal processing across different timing contexts, comprising a core-timing network, as well as areas that are activated in a context-dependent/sensory-specific fashion (e.g., visual cortex or cerebellum - see Chen \& Zhou, 2014; Teki et al., 2012 - Fig. 1). The core-timing network consists of corticothalamic-basal ganglia circuits activated primarily by dopamine and glutamate (Cheng et al., 2006; Coull et al., 2011, 2013; Jones \& Jahanshahi, 2014; MacDonald \& Meck, 2004; Matell et al., 2003; Merchant et al., 2013; Yin \& Meck, 2014). The interaction between these two sets of structures supports the specific temporal judgments in a task. In the case of sub-second intervals, the RS and GABA-related effects observed in the cortex are presumably produced by "additive" as opposed to "multiplicative" effects, i.e., changes in the threshold manifold (Mitry et al., 2013) required to initiate timing of the "to-be-timed" stimulus as opposed to the oscillation frequency of the putative clock during the course of the entire stimulus duration (see Cheng et al., 2007; Lake et al., 2014; Lake \& Meck, 2013; Matthews, 2011a, b). Future work should be aimed at separating threshold dynamics from speed effects for suband supra-second durations in order to better understand the dynamics of temporal processing and how satellite (i.e., local/peripheral) and core interval-timing mechanisms are integrated with circadian clocks and more general cognitive processes (e.g., Agostino et al., 2011; Boehm, Van Maanen, Forstmann, \& Van Rijn, 2014; Bausenhart et al., 2010; Buhusi \& Meck, 2005; Gu et al., in press b; Henry \& Hermann, 2014; Matthews \& Meck, 2014, submitted; Meck et al., 2012; Méndez et al., 2014; Merchant et al., 2013; Polyn \& Sederberg, 2014; Shi et al., 2013; Taatgen, Van Rijn \& Anderson, 2007; Tucci et al., 2014; Van Rijn et al., 2011, in press).

\section{Core Timing Network}
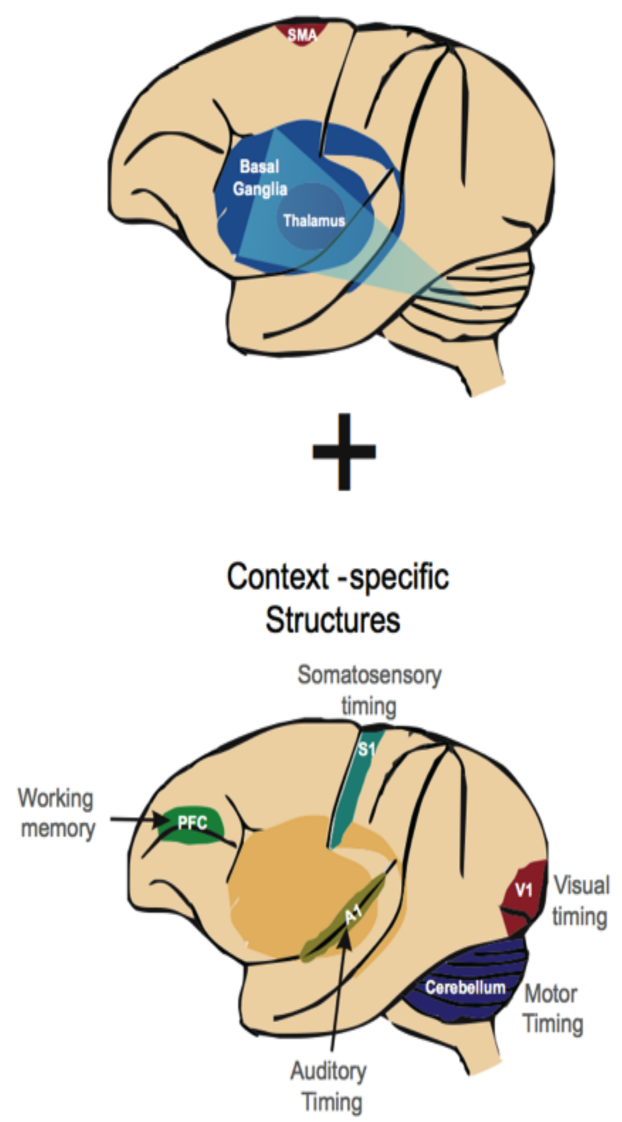

Figure 1. The unified timing model proposes that temporal estimation depends on the interaction of multiple areas, including regions that are context/sensory specific as well as those that form the core-timing network (i.e., cortico-thalamic-basal ganglia circuits). The interaction between these two sets of structures supports temporal processing in a particular timing procedure. The blue triangle in the upper panel corresponds to the dopaminergic system innervating the basal ganglia. The diagram is adapted from Figure 2 from Merchant et al. (2013) - see also Figure 1 from Teki et al. (2012) and Figure 6 from Allman et al. (2014) for additional details of the unified timing model.

Recent work by Rammsayer and colleagues (e.g., Rammsayer, 2014; Rammsayer \& Verner, 2014) has questioned whether the effects of nontemporal stimulus 
attributes (e.g., brightness, numerosity, complexity, or size) on time perception are mediated by a common mechanism (e.g., coding efficiency or a generalized magnitude system - see Aagten-Murphy et al., 2014; Eagleman \& Pariyadath, 2009; Walsh, 2003), a series of distinct elementary processes specific to the timing task, or response-rule and decision biases (e.g., Van Rijn et al., in press; Yates et al., 2012). Rammsayer and Verner (2014) showed that the effect of non-temporal stimulus size on perceived duration generalizes across different timing tasks and is not limited to comparative duration judgments. Moreover, their findings indicated that these effects are independent of the amount of attention allocated to stimulus size, the conclusion being that nontemporal stimulus attributes need not enter consciousness in order to affect perceived duration. Similar arguments can be made in the case of modality differences (e.g., Berry et al., 2014; Lustig \& Meck, 2011; Penney, 2003), the parallel timing of multiple intervals (de Montalembert \& Mamassian, 2012; Van Rijn \& Taatgen, 2008), and sub-second and supra-second stimulus durations (Melgire et al., 2005; Rammsayer \& Troche, 2014). Taken together, these effects argue for a common mechanism that might involve coding efficiency.

In summary, we suggest that the encoding of stimulus duration occurs both locally in primary sensory areas utilizing the intrinsic computation of neural circuits and/or at more central levels where the cortical inputs converge with other systems (Merchant et al., 2013). The specificity of interval timing observed at the local level likely relies on coding efficiency as well as improvements in reading the neural dynamic generated by the specific neural circuits (Bueti \& Buonomano, in press; Eagleman \& Pariyadath, 2009; Gotts et al., 2012). In contrast, the generalization of interval timing observed at the central level likely relies on coincidence-detection of patterns of cortical activity across a broad area (Gu et al., in press b; Kösem et al., 2014; Merchant et al., 2011; 2013; Van Rijn et al., in press).

\section{Acknowledgments}

This work was supported, in part, by a Marie SkłodowskaCurie Intra-European Fellowship within the 7 th European Community Framework Programme to DBT and a James McKeen Catell Fellowship to WHM.

\section{References}

Aagten-Murphy, D., Iversen, J. R., Williams, C. L., \& Meck, W. H. (2014). Novel inversions in auditory sequences provide evidence for spontaneous subtraction of time and number. Timing Time Percept., 2, 188-209.
Aghdaee, S. M., Battelli, L., \& Assad, J. A. (2014). Relative timing: From behaviour to neurons. Philos. Trans. R. Soc. B 369(1637), 20120472.

Agostino, P. V., Golombek, D. A., \& Meck, W. H. (2011). Unwinding the molecular basis of interval and circadian timing. Front. Integr. Neurosci., 5:64.

Allan, L. G. (1979). The perception of time. Percept. Psychophys., 26, 340-354.

Allman, M. J., \& Meck, W. H. (2012). Pathophysiological distortions in time perception and timed performance. Brain, 135, 656-677.

Allman, M. J., Teki, S. Griffiths, T. D., \& Meck, W. H. (2014). Properties of the internal clock: First- and second-order principles of subjective time. Annu. Rev. Psychol., 65, 743-771.

Bastos, A. M., Usrey, W. M., Adams, R. A., Mangun, G. R., Fries, P., \& Friston, K. J. (2012). Canonical microcircuits for predictive coding. Neuron, 76, 695-711.

Bausenhart, K. M., Rolke, B., Seibold, V. C., \& Ulrich, R. (2010). Temporal preparation influences the dynamics of information processing: Evidence for early onset of information accumulations. Vision Res., 50, 1025-11034.

Berry, A. S., Li, X., Lin, Z., \& Lustig, C. (2014). Shared and distinct factors driving attention and temporal processing across modalities. Acta Psychol. (Amst.), 147, 42-50.

Birngruber, T., Schröter, H., \& Ulrich, R. (2014). Duration perception of visual and auditory oddball stimuli: Does judgment task modulate the temporal oddball effect? Attent. Percept. Psychophys., 76, 814-828.

Boehm, U., Van Maanen, L., Forstmann, B., \& van Rijn, H. (2014). Trial-by-trial fluctuations in CNV amplitude reflect anticipatory adjustment of response caution. NeuroImage, 96, 95-105.

Brunet, N. M., Bosman, C. A., Vink, M., Roberts, M., Oostenveld, R., Desimone, R., De Weerd, P., \& Fries, P. (2014). Stimulus repetition modulates gamma-band synchronization in primate visual cortex. Proc. Natl. Acad. Sci. U.S.A., 111,3626-3631.

Bueti, D., \& Buonomano, D. V. (in press). Temporal perceptual learning. Timing Time Percept.

Buhusi, C. V., \& Meck, W. H. (2005). What makes us tick? Functional and neural mechanisms of interval timing. Nat. Rev. Neurosci., 6, 755-765.

Buhusi, M., Scripa, I., Williams, C. L., \& Buhusi, C. V. (2013). Impaired interval timing and spatial-temporal integration in mice deficient in CHL1, a gene associated with schizophrenia. Timing Time Percept., 1, 21-38.

Chen, L., \& Zhou, X. (2014). Fast transfer of crossmodal time interval training. Exp. Brain Res., 232, 1855-1864. 
Cheng, R. K., Ali, Y. M., \& Meck, W. H. (2007). Ketamine "unlocks" the reduced clock-speed effect of cocaine following extended training: Evidence for dopamineglutamate interactions in timing and time perception. Neurobiol. Learn. Mem., 88, 149-159.

Cheng, R. K., MacDonald, C. J., \& Meck, W. H. (2006). Differential effects of cocaine and ketamine on time estimation: Implications for neurobiological models of interval timing. Pharmacol. Biochem. Behav., 85, 114-122.

Coull, J. T., Cheng, R. K., \& Meck, W. H. (2011). Neuroanatomical and neurochemical substrates of timing. Neuropsychopharmacology, 36, 3-25.

Coull, J. T., Hwang, H. J., Leyton, M., \& Dagher, A. (2013). Dopaminergic modulation of motor timing in healthy volunteers differs as a function of baseline DA precursor availability. Timing Time Percept., 1, 77-98.

De Baene, W., \& Vogels, R. (2010). Effects of adaptation on the stimulus selectivity of macaque inferior temporal spiking activity and local field potentials. Cereb. Cortex, 20, 2145-2165.

de Gardelle, V., Waszcuk, M., Egner, T., \& Summerfield, C. (2013). Concurrent repetition enhancement and suppression in extrastriate visual cortex. Cereb. Cortex 23, 2235-2244.

de Montalembert, M., \& Mamassian, P. (2012). Processing temporal events simultaneously in healthy human adults and in hemi-neglect patients. Neuropsychologia, 50, 791-799.

Donahue, M. J., Near, J., Blicher, J. U., \& Jezzard, P. (2010). Baseline GABA concentration and fMRI response. NeuroImage, 53, 392-398.

Dyjas, O., Ulrich, R. (2014). Effects of stimulus order on discrimination processes in comparative and equality judgements: Data and models. Quart. J. Exp. Psychol., 67, 1121-1150.

Eagleman, D. (2008). Human time perception and its illusions. Curr. Opin. Neurobiol., 18, 1-6.

Eagleman, D. M., \& Pariyadath, V. (2009). Is subjective duration a signature of coding efficiency? Philos. Trans. R. Soc. B., 364, 1841-1851.

Eagleman, D. M., Tse, P. U., Buonomano, D., Janssen, P., Nobre, A. C., \& Holcome, A. O. (2005). Time and the brain: How subjective time related to neural time. $J$. Neurosci., 25, 10369-10371.

Ekstrom, A. (2010). How and when the fMRI bold signal relates to underlying neural activity: The danger in dissociation. Brain Res. Rev., 62 (2), 233-244.

Gibbon, J., Church, R. M., \& Meck, W. H. (1984). Scalar timing in memory. Ann. N.Y. Acad. Sci., 423, 52-77.

Giersch, A., \& Herzog, M. H. (2004). Lorazepam strongly prolongs visual information processing. Neuropsychopharmacology, 29, 1386-1394.
Gonsalves, B. D., Kahn, I., Curran, T., Norman, K. A., \& Wagner, A. D. (2005). Memory strength and repetition suppression: Multimodal imaging of medial temporal cortical contributions to recognition. Neuron, 47 (5), $75^{-}$ 761.

Gotts, S., Chow, C., \& Martin, A. (2012). Repetition priming and repetition suppression: A case for enhanced efficiency through neural synchronization. Cogn. Neurosci., 3, 227-237.

Grill-Spector, K., Henson, R., \& Martin, A. (2006). Repetition and the brain: Neural models of stimulusspecific effects. Trends Cogn. Sci., 10, 14-23.

Gu, B.-M., Jurkowski, A. J., Lake, J. I., Malapani, C., \& Meck, W. H. (in press). Bayesian models of interval timing and distortions in temporal memory as a function of Parkinson's disease and dopamine-related error processing. In A. Vatakis \& M.J. Allman (Eds.), Time distortions in mind: Temporal processing in clinical populations. Boston, MA: Brill Academic Publishers.

Gu, B.-M., \& Meck, W. H. (2011). New perspectives on Vierordt's law: Memory-mixing in ordinal temporal comparison tasks. Lect. Notes Comp. Sci., LNAI 6789, 6778.

Gu, B.-M. van Rijn, H., \& Meck, W. H. (2015). Oscillatory multiplexing of neural population codes for interval timing and working memory. Neurosci. Biobehav. Rev., $48,160-185$.

Heilbronner, S. R., \& Meck, W. H. (2014). Dissociations between interval timing and intertemporal choice following administration of fluoxetine, cocaine, or methamphetamine. Behav. Process., 101, 123-134.

Hellström, Å. (1985). The time-order error and its relatives: Mirrors of cognitive processes in comparing. Psychol. Bull., 97, 35-61.

Henry, M. J., \& Hermann, B. (2014). Low-frequency neural oscillations support dynamic attending in temporal context. Timing Time Percept., 2, 62-86.

Henson, R. N., Rylands, A., Ross, E., Vuilleumeir, P., Rugg, \& M. D. (2004). The effect of repetition lag on electrophysiological and haemodynamic correlates of visual object priming. NeuroImage, 21, 1674-1689.

Jones, C. R. G., \& Jahanshahi, M. (2014). Contributions of the basal ganglia to temporal processing: Evidence from Parkinson's disease. Timing Time Percept., 2, 87-127.

Jovanovic, J. N., \& Thomson, A. M. (2011). Development of cortical GABergic innervation. Front. Cell. Neurosci., 5:14.

Kim, E. J., \& McAuley, J. D. (2013). Effects of pitch distance and likelihood on the perceived duration of deviant auditory events. Attent. Percept. Psychophys., 75, 1547$155^{8}$. 
Kononowicz, T. W., \& van Rijn, H. (2014). Decoupling interval timing and climbing neural activity: A dissociation between $\mathrm{CNV}$ and $\mathrm{NiP}_{2}$ amplitudes. $J$. Neurosci., 34, 2931-2939.

Kösem, A., Gramfort, A., \& van Wassenhove, V. (2014). Encoding of event timing in the phase of neural oscillations. NeuroImage, 92, 274-284.

Kovács, G., Kaiser, D., Kaliukhovich, D. A., Vidnyánszky, Z. \& Vogels, R. (2013). Repetition probability probability does not affect fMRI repetition suppression for objects. J. Neurosci., 33, 9805-9812.

Lake, J. I., LaBar, K. S., \& Meck, W. H. (2014). Hear it playing low and slow: How pitch level differentially influences time perception. Acta Psychol. (Amst.), 149, 169-177.

Lake, J. I., \& Meck, W. H. (2013). Differential effects of amphetamine and haloperidol on temporal reproduction: Dopaminergic regulation of attention and clock speed. Neuropsychologia, 51, 284-292.

Larsson, J., \& Smith, A. T. (2012). fMRI repetition suppresion: Neuronal adaptation or stimulus expectation? Cereb. Cortex, 22, 567-576.

Lewis, P. A., \& Meck, W. H. (2012). Time and the sleeping brain. The Psychologist, 25, 594-597.

Logothetis, N. (2003). The underpinnings of the BOLD functional magnetic resonance imaging signal. $J$. Neurosci., 23, 3963-3971.

Logothetis, N., Pauls, J., Augath, M., Trinath, T., \& Oeltermann, A. (2001). Neurophysiological investigation of the basis of the fMRI signal. Nature, 412, 150-157.

Luk, C.-H., \& Wallis, J. D. (2013). Choice coding in frontal cortex during stimulus-guided or action-guided decision-making. J. Neurosci., 33, 1864-1871.

Lustig, C., Matell, M. S., \& Meck, W. H. (2005). Not “just" a coincidence: Frontal-striatal synchronization in working memory and interval timing. Memory, 13, 441-448.

Lustig, C., \& Meck, W. H. (2011). Modality differences in timing and temporal memory throughout the lifespan. Brain Cogn., 77, 298-303.

Maccotta, L., \& Buckner, R. L. (2004). Evidence for neural effects of repetition that directly correlate with behavioral priming. J. Cogn. Neurosci., 16, 1625-1632.

MacDonald, C. J., Fortin, N. J., Sakata, S., \& Meck, W. H. (2014). Retrospective and prospective views on the role of the hippocampus in interval timing and memory for elapsed time. Timing Time Percept., 2, 51-61.

MacDonald, C. J., \& Meck, W. H. (2004). Systems-level integration of interval timing and reaction time. Neurosci. Biobehav. Rev., 28, 747-769.

Matell, M. S., \& Meck, W. H. (2000). Neuropsychological mechanisms of interval timing behaviour. BioEssays, 22, 94-103.
Matell, M. S., \& Meck, W. H. (2004). Cortico-striatal circuits and interval timing: Coincidence-detection of oscillatory processes. Cogn. Brain Res., 21, 139-170.

Matell, M. S., Meck, W. H., \& Nicolelis, M. A. L. (2003). Interval timing and the encoding of signal duration by ensembles of cortical and striatal neurons. Behav. Neurosci., 117, 760-773.

Matthews, W. J. (2011a). Can we use verbal estimation to dissect the internal clock? Differentiating the effects of pacemaker rate, switch latencies, and judgment processes. Behav. Process., 86, 68-74.

Matthews, W. J. (2011b). Stimulus repetition and the perception of time: The effects of prior exposure on temporal discrimination, judgment, and production. PLoS ONE, 6(5): e19815.

Matthews, W. J., \& Meck, W. H. (submitted). Temporal cognition: Beyond simple interval estimation.

Matthews, W. J., \& Meck, W. H. (2014). Time perception: The bad news and the good. WIREs Cogn. Sci., 5, 429-446.

Matthews, W. J., Stewart, N., \& Wearden, J. H. (2011). Stimulus intensity and the perception of duration. J. Exp. Psychol. Hum. Percept. Perform., 37, 303-313.

Mayo, J. P., \& Sommer, M.A. (2008). Neuronal adaptation caused by sequential visual stimulation in the frontal eye field. J. Neurophysiol., 100, 1923-1935.

Mayo, J. P., \& Sommer, M. A. (2013). Neuronal correlates of visual time perception at brief timescales. Proc. Natl. Acad. Sci. U.S.A., 110, 1506-1511.

Meck, W. H. (1983). Selective adjustment of the speed of internal clock and memory processes. J. Exp. Psychol. Anim. Behav. Process., 9, 171-201.

Meck, W. H. (1996). Neuropharmacology of timing and time perception. Cogn. Brain Res., 3, 227-242.

Meck, W. H. (2006). Neuroanatomical localization of an internal clock: A functional link between mesolimbic, nigrostriatal, and mesocortical dopaminergic systems. Brain Res., 1109, 93-107.

Meck, W. H., \& Benson, A. M. (2002). Dissecting the brain's internal clock: How frontal-striatal circuitry keeps time and shifts attention. Brain Cogn., 48, 195-211.

Meck, W. H., \& Church, R. M., \& Matell, M. S. (2013). Hippocampus, time, and memory - A retrospective analysis. Behav. Neurosci., 127, 642-654.

Meck, W. H., Doyère, V., \& Gruart, A. (2012). Interval timing and time-based decision making. Front. Integrat. Neurosci., 6, 13 .

Meck, W. H., Hinton, S. C., \& Matell, M. S. (1998). Coincidence-detection models of interval timing: Evidence from fMRI studies of cortico-striatal circuits. NeuroImage, 7, S281.

Meck, W. H., \& Malapani, C. (2004). Neuroimaging of interval timing. Cogn. Brain Res., 21, 133-137. 
Meck, W. H., Penney, T. B., \& Pouthas, V. (2008). Corticostriatal representation of time in animals and humans. Curr. Opin. Neurobiol., 18, 145-152.

Melgire, M., Ragot, R., Samson, S., Penney, T. B., Meck, W. H., \& Pouthas, V. (2005). Auditory/visual duration bisection in patients with left or right medial-temporal lobe resection. Brain Cogn., 58, 119-124.

Méndez, J. C., Pérez, O., Prado, L., \& Merchant, H. (2014). Linking perception, cognition, and action: Psychophysical observations and neural network modelling. PLoS ONE, 9(7): e102553.

Merchant, H., Bartolo, R., Méndez, J. C., Pérez, O., Zarco, W., \& Mendoza, G. (2011). What can be inferred from multiple-task psychophysical studies about the mechanisms for temporal processing? Lect. Notes Comp. Sci., LNAI 6789, 207-229.

Merchant, H., Harrington, D. L., \& Meck, W. H. (2013). Neural basis of the perception and estimation of time. Annu. Rev. Neurosci., 36, 313-336.

Merzagora, A. R., Coffey, T. J., Sperling, M. R., Sharan, A., Litt, B., Baltuch, G., \& Jacobs, J. (2014). Repeated stimuli elicit diminished high-gamma electrocorticographic responses. NeuroImage, 85, 844-852.

Mitry, J., McCarthy, M., Kopell, N., \& Wechselberger, M. (2013). Excitable neurons, firing threshold manifolds and canards.J. Math. Neurosci., 3:12.

Muthukumaraswamy, S. D., Edden, R. A. E., Jones, D. K., Swettenham, J. B., \& Singh, K. D. (2009). Resting GABA concentration predicts peak gamma frequency and fMRI amplitude in response to visual stimulation. Proc. Natl. Acad. Sci. U.S.A., 106, 8356-8361.

Naccache, L., \& Dehaene, S. (2001). The priming method: Imaging unconscious repetition priming reveals abstract representation of number in the parietal lobes. Cereb. Cortex, 11, 966-974.

Ng, K. K., Tobin, S., \& Penney, T. B. (2011). Temporal accumulation and decision processes in the duration bisection task revealed by contingent negative variation. Front. Integr. Neurosci., 5:77.

Noguchi, Y., \& Kakigi, R. (2006). Time representations can be made from nontemporal information in the brain: an MEG study. Cereb. Cortex, 16, 1797-1808.

Northoff, G., Walter, M., Schulte, R. F., Beck, J., Dydak, U., Henning, A., Boeker, H., Grimm, S., \& Boesiger, P. (2007). GABA concentrations in the human anterior cingulate cortex predict negative BOLD responses in fMRI. Nat. Neurosci., 10, 1515-1517.

Pariyadath, V., \& Eagleman, D. M. (2007). The effect of predictability on subjective duration. PLOS ONE, 2(11): e1264.
Pariyadath, V., \& Eagleman, D. M. (2012). Subjective duration distortions mirror neural repetition suppression. PLoS ONE, 7(12): e49362.

Penney, T. B. (2003). Modality differences in interval timing. In W. H. Meck (ed.), Functional and neural mechanisms of interval timing (pp. 209-233). Boca Raton: CRC Press.

Penney, T. B., Gibbon, J., \& Meck, W. H. (2000). Differential effects of auditory and visual signals on clock speed and temporal memory. J. Exp. Psychol. Hum. Percept. Perform., 26, 1770-1787

Penney, T. B., Gibbon, J., \& Meck, W. H. (2008). Categorical scaling of duration bisection in pigeons (Columba livia), mice (Mus musculus), and humans (Homo sapiens). Psychol. Sci., 19, 1103-1109.

Polyn, S. M., \& Sederberg, P. B. (2014). Brain rhythms in mental time travel. NeuroImage, 85, 678-684.

Puts, N. A., \& Edden, R. A. (2012). In vivo magnetic resonance spectroscopy of GABA: A methodological review. Prog. Nucl. Magn. Reson. Spectrosc., 6o, 29-41.

Rammsayer, T. (1992). Effects of benzodiazepine-induced sedation on temporal processing. Hum. Psychopharmacol., 7, 311-318.

Rammsayer, T. H. (1994). Effects of practice and signal energy on duration discrimination of brief auditory intervals. Percept. Psychophys., 55, 454-464.

Rammsayer, T. H. (1999). Neuropharmacological evidence for different timing mechanisms in human. Quart. J. Exp. Psychol., 52B, 273-286.

Rammsayer, T. H. (2014). The effects of type of interval, sensory modality, base duration, and psychophysical task on the discrimination of brief time intervals. Atten. Percept. Psychophys., 76, 1185-1196.

Rammsayer, T. H., \& Troche, S. J. (2014). In search of the internal structure of the processes underlying interval timing in the sub-second and the second range: The confirmatory analysis approach. Acta Psychol. (Amst.), 147, 68-74.

Rammsayer, T. H., \& Verner, M. (2014). The effect of nontemporal stimulus size on perceived duration as assessed by the method of reproduction. J. Vision, 14, 110.

Rao, R. P. N., \& Ballard, D. H. (1999). Predictive coding in the visual cortex: A functional interpretation of some extra-classical receptive-field effects. Nat. Neurosci., 2, 79-87.

Rose, D., \& Summers, J. (1995). Duration illusions in a train of visual stimuli. Perception, 24, 1177-1187.

Merzagora, A. R., Coffey, T. J., Sperling, M. R., Sharan, A., Litt, B., Baltuch, G., \& Jacobs, J. (2014). Repeated stimuli elicit diminished high-gamma electrocorticographic responses. NeuroImage, $85,844-85^{2}$. 
Sadeghi, N. G., Pariyadath, V., Apte, S., Eagleman, D. M., \& Cook, E. P. (2011). Neural correlates of subsecond time distortion in the middle temporal area of visual cortex. $J$. Cogn. Neurosci., 23, 3829-3840.

Sawamura, H., Orban, G., \& Vogels, R. (2006). Selectivity of neuronal adaptation does not match response selectivity: A single-cell study of the fMRI adaptation paradigm. Neuron, 49, 307-318.

Segaert, K., Weber, K., de Lange, F. P., Petersson, K. M., \& Hagoort, P. (2013). The suppression of repetition enhancement: A review of fMRI studies. Neuropsychologia, 51, 59-66.

Schindel, R., Rowlands, J., \& Arnold, D. H. (2011). The oddball effect: Perceived duration and predictive coding. J. Vision, 11, 1-9.

Shi, Z., Church, R. M., \& Meck, W. H. (2013). Bayesian optimization of time perception. Trends Cogn. Sci., 17, 556-564.

Smith, M. A., \& Sommer, M. A. (2013). Spatial and temporal scales of neuronal correlation in visual area $\mathrm{V}_{4} . J$. Neurosci., 33, 5422-5432.

Taatgen, N. A., van Rijn, H., \& Anderson, J. (2007). An integrated theory of prospective time interval estimation: The role of cognition, attention, and learning. Psychol. Rev., 114, 577-598.

Taatgen, N., \& van Rijn, H. (2011). Traces of times past: Representations of temporal intervals in memory. Mem. Cogn., 39, 1546-156o.

Teki, S., Grube, M., \& Griffiths, T. D. (2012). A unified model of time perception accounts for duration-based and beat-based timing mechanisms. Front. Integr. Neurosci., 5:90.

Terhune, D. B., Russo, S., Near, J., Stagg, C. J., \& Cohen Kadosh, R. C. (2014). GABA predicts time perception. J. Neurosci., 34, 4364-4370.

Tipples, J., Brattan, V., \& Johnston, P. (2013). Neural bases for individual differences in the subjective experience of short durations (less than 2 seconds). PLoS ONE, 8: e54669.

Tootell, R. B. H., Hadjikhani, N. K., Vanduffel, W., Liu, A. K., Mendola, J. D., Sereno, M. I., \& Dale, A. M. (1998). Functional analysis of primary visual cortex (vi) in humans. Proc. Natl. Acad. Sci. U.S.A., 95, 811-817.

Tse, P. U., Intriligator, J., Rivest, J., \& Cavanagh, P. (2004). Attention and the subjective expansion of time. Percept. Psychophys., 66, 1171-1189.

Tucci, V., Buhusi, C. V., Gallistel, C. R., Meck, W. H. (2014). Towards an integrated understanding of the biology of timing. Philos. Trans. R. Soc. B., 369, 20120470.

Ulrich, R., Nitschke, J., \& Rammsayer, T. (2006). Perceived duration of expected and unexpected stimuli. Psychol. Res., 70, 77-87. van Loon, A. M., Knapen, T., Scholte, H. S., St. JohnSaaltink, E., Donner, T. H., \& Lamme, V. A. F. (2013). GABA shapes the dynamics of bistable perception. Curr. Biol., 23, 823-827.

van Loon, A. M., Scholte, H. S., van Gaal, S., van der Hoort, B. J. J., \& Lamme, V. A. F. (2012). GABA $A_{A}$ agonist reduces visual awareness: A masking-EEG experiment. J. Cogn. Neurosci., 24, 965-974.

van Rijn, H., Gu, B.-M., \& Meck, W. H. (2014). Dedicated clock/timing-circuit theories of interval timing and timed behavior. Adv. Exp. Med. Biol., 829, 75-99.

van Rijn, H., Kononowicz, T. W., Meck, W. H., Ng, K. K., \& Penney, T. B. (2011). Contingent negative variation and its relation to time estimation: A theoretical evaluation. Front. Integr. Neurosci., 5:91.

van Rijn, H., \& Taatgen, N. A. (2008). Timing of multiple overlapping intervals: How many clocks do we have? Acta Psychol. (Amst.), 129, 365-375.

Wacongne, C., Labyt, E., van Wassenhove, V., Bekinschtein, T., Naccache, L., \& Dehaene, S. (2011). Evidence for a hierarchy of predictions and prediction errors in human cortex. Proc. Natl. Acad. Sci. U.S.A., 108, 20754-20759.

Walsh, V. (2003). A theory of magnitude: Common cortical metrics of time, space, and quantity. Trends Cogn. Sci., 7, 483-488.

Watson, T. D., Petrakis, I. L., Edgecombe, J., Perrino, A., Krystal, J. H., \& Mathalon, D. H. (2009). Modulation of the cortical processing of novel and target stimuli by drugs affecting glutamate and GABA neurotransmission. Int. J. Neuropsychopharmacol., 12, 357-370.

Yates, M. J., Loetscher, T., \& Nicholls, M. E. R. (2012). A generalized magnitude system for space, time, and quantity? A cautionary note. J. Vision, 12(7):9.

Yin, B., \& Meck, W. H. (2014). Comparison of interval timing behaviour in mice following dorsal or ventral hippocampal lesions with mice having $\delta$ opioid receptor gene deletion. Philos. Trans. R. Soc. B., 369, 20120466.

Yizhar, O., Fenno, L. E., Prigge, M., Schneider, F., Davidson, T. J., O'Shea, D. J., Sohal, V. S., Goshen, I., Finkelstein, J., Paz, J. T., Stehfest, K., Fudim, R., Ramakrishnan, C., Huguenard, J. R., Hegemann, P., \& Deisseroth, K. (2011). Neocortical excitation/inhibition balance in information processing and social dysfunction. Nature, $477,171-178$. 